\title{
El discurso antifrancés de un borbonista español. Macanaz ante El siglo de Luis XIV, de Voltaire
}

Francisco Precioso Izquierdo

Instituto de Ciências Sociais da Universidade de Lisboa

CES.XVIII, núm. 25 (2015), págs. 285-300. 


\section{RESUMEN}

La crítica y el juego de respuestas cruzadas entre franceses y españoles vertebrará buena parte de las relaciones culturales y políticas entre ambos vecinos durante el periodo Moderno. Una página más de esta polémica será escrita por don Melchor Macanaz en 1757 en sus «Notas» a El Siglo de Luis XIV de Voltaire. La obra nos servirá para analizar el discurso original de un viejo borbonista antifrancés desengañado con las autoridades francesas, hostil a todo lo relacionado con la corona de Francia e impulsor de la memoria castellana de los primeros reyes de la dinastía Borbón en España.

Palabras Clave

Melchor Macanaz; Voltaire; El siglo de Luis XIV; borbonismo; discurso.

\section{AbSTRACT}

Cultural and political relations between French and Spanish are vertebrates by criticism and answers crossed during the Modern period. A page of this controversy is written by Don Melchor Macanaz in the "Notes" to "The Age of Louis XIV" by Voltaire (1757). The work will serve to analyze the hostile speech against France of a part of the Spanish followers of the Bourbon and the construction of the Castilian memory of the first Bourbon kings in Spain.

\section{KEY WoRDS}

Melchor Macanaz; Voltaire; The Century of Louis XIV; bourbonism; speech.

Recibido: 13 de junio de 2015. Aceptado: 22 de septiembre de 2015.

Esta investigación se ha desarrollado en el Instituto de Ciências Sociais da Universidade de Lisboa gracias a una Beca de Formación Postdoctoral concedida por la Fundación Séneca, Agencia de Ciencia y Tecnología de la Región de Murcia (19816/PD/15). Asimismo, forma parte de los proyectos de investigación: «Nobilitas II- Estudios y base documental de la nobleza del Reino de Murcia, siglos XV-XIX. Segunda fase: análisis comparativos», financiado por la Fundación Séneca, Agencia de Ciencia y Tecnología de la Región de Murcia (15300/PHC/10) y «Familias e individuos: Patrones de modernidad y cambio social (siglos XVI-XXI)», financiado por el Ministerio de Ciencia e Innovación (HAR2013-48901-C6-1-R). 


\section{Introducción}

El comentario realizado por el jurista castellano Melchor Macanaz a El Siglo de Luis XIV , es uno de los textos menos conocidos del ex fiscal general del consejo de Castilla (1713-1715). En la polémica y amplia producción literaria de Macanaz, la revisión a la obra de Voltaire apenas ha encontrado referencias en la historiografía ${ }^{2}$. Menos aun lo han hecho los otros dos testimonios de la crítica dirigida por el español al autor francés. Conservadas en la Biblioteca Nacional de España, las notas de don Melchor a la regla de gobierno aprobada por Federico II bajo el título «Derecho Cristiano Universal» que Macanaz hace pasar «por la pluma del francés Mr. de Voltaire, su Consejero y de su Academia»³, así como la revisión a «La Historia de Castrioto, sobre los sucesos acaecidos en lo de Velletri y en la guerra de Italia» ${ }^{4}$ —atribuida nuevamente a Voltaire-, han pasado en gran medida inadvertidas.

En cuanto a la primera, objeto de nuestro análisis, su contenido no hace sino revisar algunos extremos de lo escrito por su autor, en especial, todos aquellos puntos relacionados con las «intrusiones», «maquinaciones», «deslealtades» o «traiciones» francesas llevadas a cabo con el único fin de «acabar con España». El propósito de don Melchor será precisamente notar la serie de «falsedades» u «ocultaciones» realizadas por el francés para edulcorar muchos de los episodios enjuiciados negativamente en su comentario.

La respuesta de Macanaz puede ser entendida como una nueva manifestación de la tradicional querella franco-española disputada principalmente en el

1 Biblioteca Nacional de España [BNE], manuscrito [ms.] 10.745, «Notas a los tres primeros tomos en octava de la Historia Universal de Francia que el francés Voltaire ha dado a luz bajo el título de Siglo de Luis XIV», fols. 115r-158r. En adelante nos referiremos a la obra como: BNE, ms. 10.745.

2 Únicamente aparece recogida en sendos catálogos de obras escritas en el siglo XvIII; véase: Francisco Aguilar Piñar, Bibliografía de autores españoles del siglo XVIII, tomo IV, Madrid, CSIC, 1981, págs. 317-332; Benito Sánchez Alonso, Fuentes de la Historia Española e Hispanoamericana, tomo II, Madrid, 1952, pág. 433.

3 BNE, ms. 10.855, «Breve Epítome del único verdadero Gobierno Christiano universal que Federico elector de Brandemburgo y Rey de Prusia ha dado a sus vasallos», f. 19r.

4 BNE, ms. 10.745, «Notas a la Historia de Castrioto», f. 51r. 
terreno de las Letras ${ }^{5}$. Una guerra de réplicas y publicaciones cruzadas entre autores franceses y españoles que mantuvo en tensión las relaciones culturales entre los tratadistas e intelectuales orgánicos al servicio de ambas coronas desde — al menos - el primer tercio del siglo XVII. En juego, la defensa de una u otra tradición como motores del desarrollo y modernidad política del continente ${ }^{6}$.

Desde esta perspectiva, interpretamos las «Notas» a El Siglo de Luis XIV como una herramienta sumamente útil para analizar una página más de la pugna entre franceses y españoles renovada a mediados del setecientos, justo a las puertas de la Ilustración. Además, con el interés añadido de la lectura llevada a cabo por su autor, don Melchor Macanaz, declarado partidario de la dinastía Borbón, circunstancia que nos permite profundizar en el texto con un doble objetivo: por un lado, aportar luz a una obra desconocida en el contexto de una aproximación global a los diversos catálogos de escritos de Macanaz, uno de los reformistas españoles más significativos de la primera mitad del siglo XVIII; por otro, conocer el discurso propio de un borbonista antifrancés como paradigma de la variedad ideológica que hubo de dominar —entre los seguidores de la nueva dinastía - en relación a la corona borbónica francesa.

\section{Catálogos e inventarios. La discutida obra de Melchor Macanaz}

La obra escrita de Melchor Macanaz (Hellín, 1670-1760) sigue siendo polémica y todavía hoy poco conocida. Las numerosas atribuciones de las que fue objeto a lo largo de los siglos XVIII y XIX, así como la incautación de sus textos en 1748 y la desaparición u ocultación posterior de buena parte de su producción, añaden confusión a la labor de datación de sus escritos.

El propio don Melchor se refirió a ellos en 1758 para cifrarlos en trescientos sesenta tomos: «dejando aparte las instrucciones enviadas (sic) a los Señores de la Paz, Villarías, Campillo, Carvajal, Ensenada, al de Huéscar, y a los señores Rey de las Dos Sicilias, y duque de Parma» ${ }^{7}$. Amplitud de memoriales,

5 Marco de rivalidad descrito brillantemente en la seminal obra de: José María Jover Zamora, 1635. Historia de una polémica y semblanza de una generación, Madrid, 1949.

6 A pesar de ello, tal y como demostró el trabajo de Schaub, la lectura dicotómica de estos episodios no puede esconder las continuas interacciones y transferencias culturales que subyacen a la rivalidad entre Francia y España, Jean-Frédéric Schaub, La Francia española. Las raíces hispanas del absolutismo francés. Madrid, Marcial Pons, 2004, págs. 13-26. En este sentido, resulta también de interés el libro colectivo editado por José Javier Ruíz IвÁÑEZ y Anne DuBet, Las monarquías española y francesa (siglos XVI-XVIII). ¿¿Dos modelos políticos? Madrid, Casa de Velázquez, 2010.

7 BNE, ms. 10.745, ff. 193v-195r. 
auxilios, críticas literarias, correspondencias, etc..., redactados sobre una notable variedad temática a lo largo de una longeva vida, circunstancias que habrían convertido a Macanaz, actor y espectador de excepción de la primera mitad del setecientos español y europeo, en un referente del «primer siglo XVIII» al estilo de Mayans o el propio Feijoo ${ }^{8}$. La desafortunada fragmentación de sus textos ha impedido llegar a conocer en mayor medida las múltiples facetas de un pensamiento propio y original que sólo en las últimas décadas ha despertado un incipiente interés 9 . En este sentido, la publicación de la biografía de Martín Gaite $(1969)^{10}$, sirvió de estimulo a una historiografía que ha comenzado a paliar —en parte- las lagunas anteriores, rescatando en unos $\operatorname{casos}^{11}$, redescubriendo en otros $^{12}$, obras escritas de puño y letra por nuestro autor.

El interés por la producción bibliográfica de don Melchor, su ordenación y catalogación, fue puesto de manifiesto en vida del propio Macanaz. Desde entonces, diferentes han sido los instrumentos elaborados en forma de catálogo con los que se ha intentado conocer su obra. Él mismo, con ocasión de su autobiografía de $1739^{13}$, se atrevió a dar un número que quedaba por debajo de los 201 escritos que nos relaciona más tarde el inventario de Campo Florido. El del

8 José Antonio Maravall, «El primer siglo XVIII y la obra de Feijoo», en Actas II Simposio sobre el Padre Feijoo y su siglo, Oviedo, 1981, págs. 151-195.

9 Julián Marías se refirió a la obra de Macanaz como «el programa de todo el siglo XVIII», Julián MARíAs, La España posible en tiempos de Carlos III, Madrid, Planeta 1988, págs. 185-193.

10 Con anterioridad a la obra de Martín Gaite, debemos señalar la temprana llamada de atención del historiador británico Kamen, quien a mediados de la década de los años sesenta del siglo pasado, contribuyó de manera decisiva a actualizar el interés por la trayectoria y obra de Melchor Macanaz, véase Henry KAMEN, «Melchor de Macanaz and the foundation of Bourbon power in Spain», The English Historical Review, LXXX/317 (1965), págs. 699-716.

11 Rosa María Alabrús Iglésies, «El pensamiento político de Macanaz», Espacio, Tiempo y Forma, Serie IV, Historia Moderna, 18/19 (2005-2006), págs. 177-201; Luis María García-Badell Arias, «Felipe V, la nobleza española y el Consejo de Castilla: la Explicación jurídica e histórica de la consulta que hizo el Real Consejo de Castilla, atribuida a Macanaz», Cuadernos de Historia del Derecho, 12 (2005), págs. 125149; Eduardo Lama Romero, Macanaz memorialista. Una aproximación a la formación del Estado Moderno, Córdoba, 2009; Julián José LoZano NAVARRo, «Los inicios del regalismo borbónico en España: un manuscrito de 1714 de Melchor de Macanaz en el Archivo de la provincia bética de la Compañía de Jesús», Chronica Nova, 26 (1999), págs. 375-391.

12 Juan Hernández Franco y Francisco Precioso Izquierdo, «Discursos enfrentados en los albores de la monarquía borbónica. Reacciones al pedimento fiscal de Macanaz», Mediterranea. Ricerche Storiche, 30 (2014), págs. 61-82; Concepción de Castro Monsalve, «La Nueva Planta del Consejo de Castilla y los pedimentos de Macanaz», Cuadernos de Historia Moderna y Contemporánea, 37 (2012), págs. 23-42; Maximiliano Barrio Gozalo, «El clero bajo sospecha a principios del siglo XVIII: El informe de Macanaz y la respuesta de los obispos», Investigaciones históricas. Época Moderna y Contemporánea, 22 (2002), págs. 47-62; Teófanes Egido López, «Las reformas fracasadas. El significado de Macanaz», en Bartolomé Escandell Bonell y Joaquín Pérez Villanueva (dirs.), Historia de la Inquisición en España y América, tomo I, Madrid, 1984, págs. 1233-1240; María Dolores Palu Berna, «Dos actitudes ante la unidad española: del conde-duque de Olivares a Melchor de Macanaz», Revista de Historia Jerónimo Zurita, 41-42 (1981), págs. 249-258.

13 BNE, ms. 20.288-59, «Vida de don Melchor de Macanaz escrita por èl mismo», fols. 1r-4v. 
embajador fue elaborado precisamente sobre la base del documento autobiográfico anterior, empleado - insistimos - como fuente principal o de referencia. La fecha de redacción — aunque la desconocemos- se puede situar en todo caso en un momento posterior a la autobiografía, más próxima a los años 1745 o 1746 a tenor de la cronología de algunas obras datadas a finales de $1744^{14}$.

Otro de los medios generalmente utilizado en la catalogación de la obra de don Melchor, es el inventario elaborado décadas después por el editor Valladares de Sotomayor $(1788)^{15}$. El documento presenta numerosas atribuciones de difícil justificación, principalmente las publicadas por Valladares en el Semanario Erudito (1787-1791), en cuyas páginas se llevó a cabo una importante labor de difusión de la obra de Macanaz ${ }^{16}$. A pesar que entre los títulos aportados por el editor localizamos textos cuya autoría resulta indiscutible, en otras ocasiones, lo que se presenta bajo la firma de don Melchor no dejan de ser más que simples atribuciones, obras cuyo contenido no desafinan con la imagen de un Macanaz sentado al estudio de la Historia, la defensa de los derechos dinásticos de Felipe $\mathrm{V}$ o las regalías del monarca ${ }^{17}$.

Completa la serie de inventarios el realizado en la segunda mitad del siglo XIX por su descendiente don Joaquín Maldonado Macanaz. La base utilizada para su elaboración remite a la documentación conservada por sus antepasados y custodiada por él mismo en su biblioteca. Los títulos del historiador vallisoletano - que según nos informa se encontraban en la librería de la casa familiar de Hellín desde $1771^{18}$ — difieren de los relacionados en el catálogo de Campo Florido, es decir, se nombran de forma diferente a pesar de que podemos suponer que se trata de las mismas obras. No obstante, en el registro de don Joaquín aparecen títulos desconocidos en 1745 o 1746, antiguos pleitos participados por

14 BNE, ms. 10.313, «Catálogo de obras que tiene escritas el señor don Melchor de Macanaz», fols. 96r-108r.

15 Semanario Erudito, tomo VII, ff. 6-10.

16 Madeline SutherLAnd, «Censura y prensa periódica a finales del siglo XVIII: El caso del Semanario Erudito (1787-1791)», Revista de Literatura, vol. LXXV, n. ${ }^{\circ} 150$ (2013), págs. 495-514; Jerónimo HerRERA Navarro, «Don Antonio Valladares de Sotomayor: Nuevos datos biográficos», Cuadernos para investigación de la literatura hispánica, 30 (2005), págs. 429-450; Ibrahim Soheim El SAYEd El SAYEd, Don Antonio Valladares de Sotomayor, autor dramático del siglo XVIII, tesis doctoral, Universidad Complutense de Madrid, 1993.

17 Francisco Precioso IzQuierdo, «De héroe regalista a sabio patriota. Construcción, representación y circulación de la memoria política de Melchor Macanaz entre dos épocas (siglos XVIII-XIX)», Investigaciones Históricas. Época Moderna y Contemporánea, 35 (2015), págs. 85-110; Ramón BALDAQuí, «El regalismo en el Semanario Erudito de valladares», Revista de Historia Moderna: Anales de la Universidad de Alicante, 4 (1984), págs. 339-386.

18 Publicado por: Joaquín Maldonado Macanaz (ed. y notas por Francisco Maldonado De Guevara), Melchor de Macanaz. Testamento político. Pedimento fiscal, Instituto de Estudios Políticos, Madrid, 1972; recogida también por: José Cano Valero, Melchor de Macanaz (1670-1760). Político y diplomático ilustrado, Ciudad Real, Instituto de Estudios Albacetenses, 2008, págs. 205-212. 
Macanaz en sus primeros años de oficio de la abogacía o trabajos cuyo contenido se relaciona con diversos acontecimientos familiares, como el tomo de «Preeminencias del oficio de Regidor de la villa de Hellín», redactado por don Melchor en la década de $1690^{19}$.

«Todo por acabar con España». Las notas de Macanaz a Voltaire y El siglo de Luis XIV

La complejidad de la obra de Macanaz suma una vuelta de tuerca al incluir los trabajos de crítica literaria llevados a cabo durante sus doce años de reclusión en La Coruña (1748-1760). Un período que trae causa directa de su última participación al servicio de la corona como plenipotenciario de la corte de Fernando VI en el congreso de Breda (1747). Su desafortunado papel en la reunión, moverá al ministro Carvajal y al embajador en París, duque de Huéscar, a organizar la farsa de su regreso a España para ser apresado y confiscados todos sus escritos y correspondencias ${ }^{20}$.

Los inventarios anteriores han obviado esta parte bien significativa de la producción del ministro murciano, a la que dedicó sus años finales de vida, prácticamente ciego y ayudado por un asistente que le leía las obras que con dificultad recibía. En el manuscrito conservado en la Biblioteca Nacional de España, número 10. 745, se anotan varios títulos que nos dan una idea de hasta qué punto continuó don Melchor, cercano a los 89 años de edad, su incesante crítica de libros, un medio que le permitiría conocer y estar al tanto de las principales novedades literarias del momento. Así, el 15 de febrero de 1758, contestaba a don José Saenz de Cenzano, cura de Ribatajada (Cuenca), una crítica a sus «Remedios a los males de la monarquía de España», trabajo que el autor agradecía con una elogiosa carta. Cuatro meses después, el 14 de junio, comenta que «llegó a mis manos un impreso anónimo de 58 páginas escrito en portugués cuyo título, Relación abreviada de la República que los Religiosos Jesuitas de las Provincias de Portugal y España establecieron [...]». De 29 de noviembre de 1758 , data el último comentario a una obra titulada «Discursos políticos, racionales y económicos para convencer al que con los gastos $[\ldots]^{21}$.

Pocos meses antes, a mediados de 1757, había informado de la conclusión de la revisión de la obra de Voltaire El siglo de Luis XIV, advirtiendo en la

19 Cano Valero, Melchor de Macanaz, pág. 28.

20 María Dolores Gómez Molleda, «El caso de Macanaz en el Congreso de Breda», Hispania. Revista española de Historia, 18 (1958), págs. 62-128.

${ }^{21}$ BNE, ms.10.745, s/n. La foliación entre paréntesis remite a partir de ahora siempre a este ms. 
misma nota: «con los reparos que al leerla deprisa por ser de un oficial de tropas me han ocurrido» (BNE, ms.10.745, s/n.). En este sentido, parece que el modo de acceso a la obra pudo ser similar al empleado en otras ocasiones, como en el caso del Teatro Crítico Universal de Feijoo ${ }^{22}$, cuyo documento le habría sido facilitado por uno de los oficiales encargados de su custodia.

Los datos que proporciona don Melchor en el manuscrito hacen referencia a la lectura de los «3 tomos en 8. ${ }^{a} »$ del libro de «Mr. de Voltaire, francés que se pasó a la Corte del Rey de Prusia y ésta es la tercera que ha impreso esta obra desde el año 1753» (BNE, ms. 10.745, fol. 117r.). Como él mismo referirá, apenas le bastaron dos semanas para realizar el trabajo: «lo firmé de mi nombre [...] hoy 6 de julio de 1757, esto desde 24 de junio que son 13 días» (BNE, ms. 10.745, fol. 117r.).

El comentario de Macanaz sigue la estructura original de El siglo de Luis XIV, organizado en tres grandes tomos, de los que don Melchor hace notar aquello que le parece de interés en cada momento. No hay que olvidar que el verdadero propósito de Voltaire, más que trazar una historia del reinado, se dirigía a «pintar [...] el espíritu de los hombres en el siglo más ilustrado que haya habido jamás ${ }^{23}$, por lo que se entiende su extensión sobre los principales acontecimientos políticos, bélicos, diplomáticos y culturales de su tiempo. Si la idea central de su autor quedaba clara al comienzo de la obra (la Francia de Luis XIV sería el periodo de la historia universal que más se acerca a la perfección), Macanaz inicia su análisis refiriéndose a los «disparates [de Voltaire] en honor de los franceses» (BNE, ms.10. 745, f. 117v.). El tono general de su crítica es bastante directo, impugnando pasajes de la historia de Francia olvidados o pasados por alto, descuidos interpretados por Macanaz como una estrategia de Voltaire para engañar sobre las verdaderas intenciones de los gobiernos franceses, es decir, acabar con España.

El discurso francófobo de Macanaz no representaba una total novedad. A pesar de los intentos esporádicos de ministros como Ensenada y su proyectado acercamiento a la corona francesa ${ }^{24}$, muchos otros políticos de su tiempo habían optado por la actitud contraria. En el caso de don Melchor, sus años en el exilio (1715-1748) habían forjado en él la imagen de Francia como aliada interesada de la monarquía española. El eje que articulaba su posición remitía continuamente a la denuncia de las «traiciones» a Felipe V por parte de su propia familia y la indiferencia mostrada por las autoridades francesas en la colocación de

22 Francisco Precioso IzQuierdo, Poder político y movilidad familiar en la España moderna. Los Macanaz (siglos XVII-XIX), Tesis Doctoral inédita, Universidad de Murcia, págs. 275-288.

23 Utilizamos la edición de: El Siglo de Luis XIV, Fondo Cultura Económica, México D. F., 1978, pág. 7.

24 José Luis Gómez URdáÑ̃z, El proyecto reformista de Ensenada, Milenio, 1996, págs. 59-81. 
los infantes españoles, objetivo prioritario de la diplomacia hispánica entre las décadas de 1730 y $1740^{25}$.

La animadversión hacia los dirigentes franceses iría en aumento tras su fracasado papel en el congreso de Breda (1747). Achacado su yerro a las intrigantes maniobras de los representantes de Luis $\mathrm{XV}^{26}$, apenas disimulará desde entones su lectura abiertamente hostil a lo francés. Desengañado del todo, no resulta extraña su advertencia al recién nombrado embajador español en París, duque de Huéscar, en mayo de 1747: «He vivido 30 años en ese reino [Francia], registrado cuanto sus escritores han publicado en todas materias de Estado, Historia y Religión, y en todo han tirado a destruirnos, pero desde 1700 acá, lo han hecho con capa de amigos, con corazones de lobos» ${ }^{27}$.

Sin embargo, donde mejor refleja Macanaz la denuncia de la tradición francesa más antiespañola posible, será en sus comentarios a la obra de Voltaire. Gran conocedor de la historia y de los historiadores de uno y otro lado de los Pirineos, recurrirá a ellos en varias ocasiones para justificar lo que consideraba un fin casi natural entre los franceses. En este sentido, resulta paradigmático que inicie su crítica haciendo referencia al propio Carlomagno, a quien —ya en las primeras páginas - señalará como el principal responsable de la situación postergada de España:

[...] poco le faltó a la Casa de Austria para ser sola en Europa, lo dice por la España; y calla que aun con los 770 años que esta estuvo dominada de los mahometanos sin los artificios de Carlo Magno y de los que con él inventaron a desunión del Imperio y el sacerdocio, aun sería la España única árbitra (sic) de todo el orbe (BNE, ms. 10.745, fols. 117v-118r.).

Inmediatamente después - y al hilo de lo escrito por Voltaire- emprende la revisión del reinado de Luis XIV. El primer comentario se dirige a la descalificación de la expansión francesa llevada a cabo por el centro y norte de Europa entre las décadas de 1660 y $1680^{28}$, un proceso interpretado por Macanaz en clave de agresión a una España mal gobernada: «porque el rey Felipe IV en su abandono y Carlos II en su minoría de edad [...] lo dejaron todo en abandono» (BNE, ms. 10. 745, fol. 118v.). Las conquistas de las plazas de Ath, Charleroi, Tournai, Furnes, Armentières, Courtrai y Douai — confirmadas en el Tratado

\footnotetext{
25 Francisco Precioso Izquierdo, Poder político y movilidad familiar, págs. 249-259 y 268-275.

26 María Dolores Gómez Molleda, «El caso de Macanaz», págs. 62-128.

27 Archivo Ministerio de Asuntos Exteriores de España [AMEE], manuscritos [ms.], 218, f. 254r.

28 La imagen inversa, es decir, la construida en Francia sobre la política expansionista de Luis XIV, ha sido bien perfilada por Jean-Frédéric Schнuв, La Francia española, págs. 127-148.
} 
de Aix-la-Chapelle (1668) - serían para Macanaz «todas a costa de España» (BNE, ms. 10. 745, fol. 120r.). Más hiriente todavía sería la posterior Paz de Nimega (1678) por la que Luis XIV «le quitó a la España el Franco Condado, Dunquerque y la mitad de los Estados de Flandes» (BNE, ms. 10. 745, fols. 120r-120v.), razón por la que a la altura de la Paz de Rijswijk (1697) se explica que «la Francia era árbitra (sic) de Europa y cedió lo que no podía mantener» (BNE, ms. 10. 745, fol. 121r.).

Para Macanaz, la política expansionista de Luis XIV no merecería ser elevada como ejemplo de conducta de un rey católico. Y no sólo por «ceder el paso» a Cromwell y aliarse en Inglaterra con «quien quitó la corona e hizo cortar la cabeza a Carlos Primero, su legítimo rey en 1652» (BNE, ms. 10. 745, fol. 118v.), sino también, por haber forzado de forma tan lamentable «al Papa Inocencio XI, lo ultrajó bien en su Corte, y quiso disponer del electorado de Colonia, todo por pura vanidad» (BNE, ms. 10. 745, fol. 120v.).

La guerra de Sucesión española y el papel jugado por buena parte de la familia de Luis XIV contra Felipe V, le permitirá retratar con minuciosidad la doble moral francesa respecto a España. Leyendo las notas de Macanaz, sorprende todavía la viveza del recuerdo y lo detallado de muchas de sus descripciones, mezcla de simples rumores con otros hechos fidedignos evocados parcialmente. En este sentido, destaca la narración de una supuesta trama urdida desde Versalles (imputada al duque de Borgoña) que tendría como objetivo evacuar de España a Felipe $\mathrm{V}$ tras la incursión de las tropas austracistas en el Madrid de 1706:

Los que entraron por Portugal aclamaron al archiduque en Madrid y en Toledo; y recibida la noticia en Versalles en la Junta que se tuvo [...] propuso que Felipe V y los castellanos de su séquito se les embarcase y llevase al Nuevo Mundo, y se abandonase la España a los enemigos; pero Felipe V, la Reina su mujer y los castellanos se burlaron de todos (BNE, ms. 10. 745, fol. 122r.).

Frente a la lectura volteriana de la batalla de Almansa como gran logro del ejército francés al mando del duque de Orleans, Macanaz insiste en ajustar el verdadero protagonismo de unos y otros:

Aquí la batalla de Almansa en 25 de abril de 1707 y el duque de Orleans, que llegó un día después, dice que esta victoria fue de las tropas francesas ayudadas de las españolas, mientras cuatro solos regimientos franceses que habían con estar en el centro dejaron las armas y banderas y huyeron (BNE,ms. 10. 745, fol. 122r.). 
Este pretexto le permitirá recordar, con evidente ánimo de denuncia, ciertos planes diseñados por el propio duque de Borgoña, encaminados —según Macanaz- a forzar la renuncia de Felipe V (su hermano) a la corona de España. Por esta razón, traerá a colación una interpretación bastante hilvanada de la serie de sucesos que tendrían lugar en el frente catalán durante la guerra:

[...] y no se da por entendido, que el Rey Felipe $V$ envió todos los franceses a Francia por haber los castellanos visto que el mariscal Besons, que los mandaba, a todo convino clandestinamente con el conde Guido Starhemberg, general austríaco, de desarmar a los castellanos para precisar a Felipe $\mathrm{V}$ a dejar la España y volverse a Francia; y en efecto, llegó el caso de venir a la batalla los dos ejercitos en el campo de Balaguer y en el movimiento de los enemigos y el orden que el de Besons dio a los suyos, reconocieron los castellanos que los franceses y alemanes iban a acabar con ellos si no se rendían. Arrestaron al mariscal de Besons y avisaron al Rey al punto fuese allá y el de Besons puesto a sus pies le pidió perdón, y le entregó las órdenes que el de Borgoña, su hermano de Felipe V, le había dado para desarmarlos y así podía llevarlo a él a Francia. Felipe $\mathrm{V}$ se quedó con las órdenes y le hizo al de Besons que con todos los franceses se volviese a Francia y quedó con sólo sus castellanos (BNE, ms.10. 745, fols. $122 \mathrm{v}-123 \mathrm{r}$.).

Si los Borbones de Francia merecen para Macanaz todo el descrédito posible, no ocurrirá lo mismo con la pareja real de España. Felipe $V$ y su primera esposa, María Luisa Gabriela de Saboya —no tanto Isabel de Farnesio- son elevados como auténticos reyes «castellanos», capaces de resistir las traiciones de su familia y no plegarse a los planes de Versalles, dirigidos únicamente a conseguir la renuncia del monarca: «En agosto de 1709, el Gobierno de Francia ofreció reconocer por Rey de España al Archiduque Carlos y dejar en abandono a Felipe V» (BNE, ms.10. 745, fols. 123r-v.), recordará don Melchor. En este punto, acusará a Voltaire de «mentir» en su relato sobre la marcha de las tropas francesas de la Península, pues — subraya Macanaz- era «cierto que Felipe V las había echado [antes]» (BNE, ms.10. 745, fols. 123r-v.). De todos los franceses enviados por Luis XIV a España en ayuda de su nieto, sólo salvará a aquellos que compartieron con él influencia en el gobierno durante el bienio 1713-1715, en concreto, la «admirable» Princesa de los Ursinos — por quién según don Melchor conocía Felipe V todas las intrigas del duque de Orleans-y el padre Robinet (BNE, ms. 10. 745 , fol. 124r.). 
Será precisamente el duque de Orleans — regente de Francia tras la muerte de Luis XIV en 1715 - quien concentre en lo sucesivo la mayor parte de las críticas más contumaces de Macanaz. De hecho, será personificado como paradigma del gobernante intrigante y confabulador, muñidor —nada menos- que de la muerte del Delfín, del duque de Borgoña, su mujer e hijo mayor hasta de la muerte por envenenamiento de su propia hija, la duquesa de Berry «que todas sus carnes cayeron a pedazos» (BNE, ms. 10. 745, fol. 127r.). Todo, según Macanaz, para forzar a Felipe V a que «renunciase a sus derechos a la Corona de Francia que los había siempre conservado» (BNE, ms. 10. 745, fol. 127r.). El autor de la crítica señalará a Voltaire por haber «disimulado» una verdad a todas luces conocida, lo que habría hecho para «tratar de hacer la apología de Orleans» (BNE, ms. 10. 745, f. 132r.).

Otro de los blancos preferidos de Macanaz será el cardenal Fleury, consejero de Luis XV, continuador - según don Melchor- de la política antiespañola de los Borbones franceses. Prueba de ello serían las continuas usurpaciones practicadas en Italia en contra de los hijos de Felipe V: «por la Corona de Polonia vino el cardenal Fleury a sacar la Lorena para la Francia, no fue sino en cambio de la Toscana, quitándole ésta al Infante son Carlos» BNE, ms. 10. 745 , fols. $127 \mathrm{v}-128 \mathrm{r}$.).

Tanto o más que en lo político, relativizará Macanaz los éxitos del reinado de Luis XIV en lo cultural, pues también en este capítulo: «la guerra de la espada ha pasado a las plumas» (BNE, ms. 10. 745, fol. 135r.). Y es que, frente al diagnóstico sobresaliente realizado por Voltaire, don Melchor minimiza los logros culturales de los franceses oponiéndolos en este caso a los de la monarquía española. Comenzará rebatiendo el papel de la inquisición francesa en reinados precedentes: «callando que siempre tuvo la Inquisición hasta que por el edicto de Nantes, de Enrique IV, suspensa [...]; sin eso, cuanto atribuye a la Inquisición todo es falso e incierto» (BNE, ms. 10. 745, fol. 134v.). Prosigue Macanaz revisando la idea - tantas veces repetida con posterioridad - de la Francia de Luis XIV como espejo de las «artes, la filosofía y las ciencias, y otras cosas grandes». Muy al contrario, dedicará sus esfuerzos a demostrar el papel irradiante que significó la España contemporánea y su influencia en campos tan variados como el teatro, la música, la danza o la propia cirugía francesa (BNE, ms. 10. 745, fols. 135v-136v.).

El comentario de don Melchor concluye en el punto tocante a las disputas religiosas y al cuadro de «sectas protestantes» que se expandirán en Francia bajo el reinado de Luis XIV. Acusará a Voltaire de errar en el análisis sobre el origen y desarrollo de luteranos y calvinistas, un error intencionado, pues según Macanaz habría desviado el tenor de su historia para salvaguardar —otra vezla memoria de Carlomagno: 
[...] todo lo que ha escrito en el tiempo que él ha abrazado como el siglo de Luis XIV solo ha ido con él a ocultarnos que estas disputas memorables con todas las herejías, sismas y males que la Iglesia católica ha padecido y padece vienen de la desunión del sacerdocio y del imperio que el mismo Carlo Magno la ideó para ayudar a los mahometanos a acabar con la Universal Monarquía de España, que fue por lo que hizo la guerra con ellos y se casó con la hija del rey moro de Toledo (BNE, ms. 10. 745, fols. 137r-137v.).

Calvino, Lutero y el resto de «herejes» no serían — para Macanaz— sino la consecuencia de la desunión producida por el rey de los Francos, quien ya en los siglos VIII y IX se había dirigido presto contra España:

[...] del Calvinismo, aquí nos dice que el origen de esta nueva peste que tiene infesta la tierra quizás encontraría en el espíritu republicano de las primeras iglesias que en sus secretas asambleas discurrieron el modo de sujetar a los emperadores [...]. Esto lo dice para cubrir que Carlo Magno fue el autor de la división (BNE, ms. 10. 745, fol. 138r.).

Concluida su labor de revisión, don Melchor descalificará globalmente la obra escrita por Voltaire, denunciando finalmente sus verdaderos fines denigratorios y poco objetivos:

[...] divertir al Vulgo ignorante con su Historia como con sus operas y comedias y así nos dice que ésta es la tercera vez que ha reimpreso esta Historia desde el año de 1748 acá; y sin duda serán también suyas otras tres, la una en Latín con el nombre de Castrussi sobre la Guerra ajustada en la Paz de Aquisgrán [...]; y las otras anónimas sobre las resultas que son también de este autor pues va en todas ellas como en esta a desfigurar la Historia todo por acabar con la España (BNE, ms. 10. 745, fol. 14lr.).

El siglo de la barbarie de Francia. A modo de conclusión

El anti francesismo de Macanaz, visible en sus comentarios a la obra de Voltaire, será un rasgo compartido con buena parte de los administradores, políticos y gobernantes de la España de su tiempo. Ministros, secretarios o consejeros con capacidad de decisión en los asuntos de gobierno, mantendrán un discurso político que hará de la crítica indiscriminada y la sospecha permanente hacia el vecino francés, uno de sus hitos más reconocibles. Autoridades 
como el mismo Macanaz, Carvajal ${ }^{29}$, Wall ${ }^{30}$ o posteriormente Floridablanca ${ }^{31}$, no rehuirán de sus escritos y memoriales la diatriba antifrancesa. Sin embargo, la posición de don Melchor presenta una serie de características que bien merecen ser subrayadas por su original formulación.

En primer lugar, el comentario de Macanaz no puede aislarse de la renovada polémica franco-española continuada en el siglo XVIII. Los ataques a la herencia hispana redoblados por los enciclopedistas y primeras plumas de la Ilustración francesa, encontrarán en don Melchor a uno de sus primeros apologistas. En este sentido, a pesar de que muchos ilustrados mantendrán cierta «ambivalencia» respecto a España — reconociendo parcialmente sus aportaciones a la historia de Europa ${ }^{32}$ — no podemos olvidar el tenor general y la recrudecida invectiva de descalificaciones que hará reaccionar a intelectuales como Forner o Cadalso a finales de la centuria ${ }^{33}$. Por eso, en la obra de Macanaz, junto a la crítica y la labor de diagnóstico de los problemas que acucian a la monarquía, la defensa de España — frente a los ataques lanzados por autores extranjeros— se entiende como un deber ineludible de todo buen vasallo. De ahí que su objetivo vaya más allá de la crítica política inmediata. El fin de Macanaz se dirige a descubrir los orígenes de la tradición anti española de los dirigentes franceses, lo que le hace remontarse nada menos que al rey Carlomagno, al que sitúa en el origen de una serie voluntaria de acciones —identificadas como una auténtica «guerra»— que llega a conectar con reinados más recientes:

Y esta guerra, que el duque de Borgoña fomentó y entretuvo desde que Felipe V su hermano fue declarado por sucesor de la Corona de España en octubre de 1700, aun después que el rey Luis XIV su abuelo, Luis Delfín, hijo de éste, y el mismo duque de Borgoña, hubieron renunciado sus derechos en el mismo Felipe

29 María Victoria López-Cordón Cortezo, «Carvajal y la política exterior de la Monarquía española», en José Miguel Delgado Barrado y José Luis Gómez Urdáñez (coords.), Los ministros de Fernando VI, Córdoba, Universidad de Córdoba, 2002, págs. 27-28.

30 Diego Téllez Alarcia, Absolutismo e Ilustración en la España del siglo XVIII. El despotismo ilustrado de D. Ricardo Wall, Madrid, Fundación Española de Historia Moderna, 2010, págs. 68-70; mismo autor, El ministerio Wall. La España «discreta» del ministro «olvidado», Madrid, Marcial Pons, 2012, págs. 70-140.

31 Didier Ozanam, «Dinastía, diplomacia y política exterior», en Pablo Fernández Albaladejo (ed.), Los Borbones. Dinastía y memoria de nación en la España del siglo XVIII, Madrid, Marcial Pons-Casa de Velázquez, 2002, pág. 41-42; Juan Hernández Franco, Aspectos de la política exterior de España en la época de Floridablanca, Murcia, Academia Alfonso X El Sabio, 1992, págs. 67-95.

32 Jean-Frédéric Schaub, La Francia española, págs. 104-105.

33 Ricardo GaRCía CárCel, La herencia del pasado. Las memorias históricas de España, Barcelona, Galaxia Gutenberg, 2011, págs. 585-592; Antonio Mestre Sanchis, Apología y crítica de España en el siglo XVIII, Madrid, Marcial Pons, 2003, págs. 47-50; François LóPEz, Juan Pablo Forner y la crisis de la conciencia española en el siglo XVIII, Valladolid, Junta de Castilla y León, 1999. 
$\mathrm{V}$, y que aun muertos el duque de Borgoña, su padre y abuelo, la prosiguieron $\mathrm{Fe}$ lipe duque de Orleans, y por muerte de éste el cardenal de Fleury, y últimamente Luis XV, que desde 1715 aún la continúa y todo ha sido y es únicamente por acabar con la España (BNE, ms. 10. 745, fol. 128v.).

Llama poderosamente la atención la continua cita y las abundantes referencias a Carlomagno, quien parece constituirse para Macanaz en un claro antecedente político de Luis XIV. Si el reinado de aquel le pareció —desde todo punto de vista - caótico y perjudicial para España, el de éste no será menos. Las conquistas territoriales de la segunda mitad del siglo XVII, las «traiciones» durante la guerra de Sucesión, las divisiones religiosas, la expansión del protestantismo, etc..., hacen concluir una idea que define la línea que presidirá sus comentarios a la obra de Voltaire: «si se conservase la posteridad — sentencia Macanaz- diría que este siglo fue de la mayor barbarie de Francia» (BNE, ms. 10. 745 , fol. 143r.).

¿Cómo es posible, cabría preguntarse en segundo lugar, la exaltación a Felipe V?, ¿cómo justifica Macanaz el reinado del primero de los Borbones en España? La respuesta — al menos una de las posibles - podemos encontrarla en la asociación con la que se refiere normalmente al monarca y «sus castellanos». Don Melchor parece querer vincular la memoria de Felipe V a Castilla, dibujando la imagen de un rey plenamente castellano, identificado con sus súbditos y en comunión de intereses con ellos. Si bien no de nacimiento, la loable ejecutoria del monarca velando por los intereses de la corona de España frente a los de su propia familia, lo convertirán en un rey menos francés. Felipe $\mathrm{V}$ y su primera mujer, María Luisa Gabriela de Saboya, se constituirían para el autor en la pareja real fundadora de la rama castellana de los Borbones, separándose de un tronco antiespañol, que quedaría reducido en Francia continuando la secular guerra contra España.

El comentario de Macanaz — visto así- presenta un indudable valor político. Más allá de las cuestiones históricas objeto de litigio, la contribución de don Melchor revela una forma muy particular de concebir el momento histórico del advenimiento al trono español de la dinastía Borbón. Sus notas a Voltaire, englobadas en el conjunto de su inmensa obra, terminan por apuntalar uno de los pilares más destacados del pensamiento político del autor, aquel que se relaciona con la defensa dinástica y la oportunidad de los Borbones. El dinasticismo de Macanaz, característica ligada normalmente a su trayectoria, se concretaría sobre la base de una defensa a ultranza de la pareja real, Felipe V y María Luisa Gabriela de Saboya, minimizando todo lo procedente de Francia y negando el influjo modernizador que representaría Luis XIV. Complemento de lo anterior 
será la sobrevaloración de la experiencia castellana — ya española para el autor-y la vindicación de España frente a los ataques sufridos por los diferentes gobiernos franceses.

Escrita a la altura de 1757, preso en la cárcel coruñesa de San Antón tras más de medio siglo de azarosa vida política, la revisión de Macanaz no hace más que señalar otra de las posibilidades dentro la gama — cada vez más amplia- de discursos y memorias políticas que caracterizarán el panorama cultural e intelectual de su tiempo ${ }^{34}$. El borbonismo antifrancés de Macanaz, muestra propia y original del jurista murciano, se nos ofrece como una nueva clave para entender uno de los proyectos más ambicioso de reforma política planteado en los inicios del siglo XVIII, una España posible que no pudo ser pero que seguirá cultivándose y madurándose a lo largo de la centuria, inscrita en el imaginario político de las generaciones siguientes, a la que se volverá como fuente de inspiración y retórica en reinados posteriores ${ }^{35}$.

34 Ricardo García Cárcel, De los elogios a Felipe V, Madrid, Centro de Estudios Políticos y Constitucionales, 2002, págs. LXI-LXII; mismo autor, «Los proyectos políticos sobre España en el siglo XVIII», en Vicente Palacio Atard (ed.), De Hispana a España. El nombre y el concepto a través de los siglos, Madrid, Colegio Libre de Eméritos, 2005, págs. 237-251.

35 Francisco Precioso Izquierdo, «De héroe regalista a sabio patriota», págs. 85-110. 